\title{
Deep-towed High Resolution multichannel seismic imaging
}

\author{
Marsset Bruno ${ }^{1, *}$, Menut Eric ${ }^{2}$, Ker Stephan ${ }^{1}$, Thomas Yannick ${ }^{1}$, Regnault Jean-Pierre ${ }^{2}$, \\ Leon Pierre ${ }^{3}$, Martinossi Henri ${ }^{3}$, Artzner Laurent ${ }^{4}$, Chenot Damien ${ }^{3}$, Dentrecolas Stephane ${ }^{3}$, \\ Spychalski B. ${ }^{5}$, Mellier G. ${ }^{6}$, Sultan Nabil ${ }^{1}$
}

1 IFREMER, REM GM, Ctr Brest, F-29280 Plouzane, France.

2 IFREMER, REM RDT, Ctr Brest, F-29280 Plouzane, France.

3 IFREMER, ISM SM S3E, ZP Bregaillon, F-83507 La Seyne Sur Mer, France.

${ }^{4}$ IFREMER, ISM SM IIDM, ZP Bregaillon, F-83507 La Seyne Sur Mer, France.

${ }^{5}$ High Tech Inc, Long Beach, MS 39560 USA.

${ }^{6}$ Sercel, F-44470 Carquefou, France.

* Corresponding author : Bruno Marsset, email address : Bruno.Marsset@ifremer.fr

\begin{abstract}
:
High Resolution (220-1050 Hz) seismic acquisition performed in deep water using deep-towed systems provides unrivalled lateral resolution when compared to conventional surface seismic. The lateral resolution of these acquisitions is controlled by the width of the first Fresnel zone, taking advantage of their positions close to the sea bottom. No current existing deep towed equipment can benefit from seismic imaging processing techniques to improve this resolution as a consequence of positioning inaccuracies. The technological developments of a digital deep-towed multichannel streamer are presented with a particular attention to positioning: each hydrophone incorporates a pitch, roll and heading sensor in order to monitor the constant deformation of the streamer in operation. The sea trials took place in July 2013 in the Mediterranean Sea. Pre-stack depth migration applied to the deep-towed multichannel data illustrates the potential of this emerging methodology in terms of penetration (12 dB improvement in Signal/Noise) and lateral resolution (mean signal wavelength: $3 \mathrm{~m}$ ) when compared with deep-towed single-channel acquisition.
\end{abstract}

\section{Highlights}

Perform deep towed High Resolution multichannel seismic imaging. Design of pressure-resistant digital hydrophones. Monitor the streamer deformation with pitch, roll, and heading sensors.

Keywords : Deep-towed seismics, Multichannel streamer, Seismic imaging 


\section{Introduction}

High Resolution (220-1050 Hz) seismic acquisition performed in great water depth using deep-towed systems arouses interest, because of its ability to provide detailed information on the sub-surface. Fields of interest include seabed instability, gas and gas-hydrate studies, and high-resolution seismic stratigraphy. The relatively low frequency content of such a system and the high Sound Level, compared to standard AUV-borne sub-bottom profilers, enable it to provide deeper penetration (hundreds of metres) and to explore rougher terrains where higher frequencies are ineffective. The keystone of this emerging 
technology is the Janus-Helmholtz piezoelectric transducer, a mature development designed for wide-band frequency modulated signals, which provides a hydrostatic pressure-independent seismic source down to 6000 meters water depth (Ker et al., 2010; Leon et al., 2009; Marsset T. et al., 2010; Riboulot et al., 2013; Rowe et al., 1993; Sultan et al., 2010, 2011)

The US Naval Research Laboratory (NRL) has pioneered the use of deep-towed high-resolution multichannel seismic acquisition. The NRL Deep Towed Acoustics Geophysics System (DTAGS) has successfully determined P-wave velocity distribution and thus acoustically characterized the medium (Chapman et al., 2002; Gettrust et al., 2004; He et al., 2002; Walia and Hannay, 1999; Wood et al., 2003, 2008). Yet, due to inadequate spatial sampling, the DTAGS could not benefit fully from the multichannel receivers for seismic imaging. Moreover, the DTAGS streamer lacks positioning accuracy to meet high-resolution seismic imaging requirements (Asakawa et al., 2009).

Taking advantages of its existing SYSIF (Deep Towed Seismic System) technology in deep-towed seismic source and single-channel data acquisition, IFREMER (French research institute for exploitation of the sea) has recently developed a multichannel streamer. This contribution presents the technological challenges of deep-towed seismic imaging issues, the technological developments need to meet these challenges and the first seismic imaging results of this emerging methodology.

\section{IMAGING REQUIREMENTS}

Adequate spatial sampling is required to avoid spatial aliasing and thus to benefit from seismic imaging. Given the high frequency content of the Janus-Helmholtz seismic source (220-1050 Hz), a trade-off has to be found between the maximum dip that can be imaged and practical technological considerations. The prototype streamer was developed with a 2 meter inter-trace spacing, which prevents spatial aliasing for dips up to $10^{\circ}$.

Velocity analysis as well as the imaging process rely on the source - receiver offset range, thus on the number of seismic channels and on the streamer length. The prototype streamer was developed with 52 seismic channels (offset : 10-112 metres) which enables velocity analysis within the upper sedimentary layers (Normal Move Out of $10 \mathrm{~ms}$ at sea floor for an altitude of 100 meters for the maximum offset). The streamer length therefore complies with the up-to $40^{\circ}$ from-vertical directivity of the Janus-Helmholtz transducer for a minimum towing altitude of 50 meters.

Operating at great water depth (over 500 meters), positioning becomes an issue, not only for relative positioning, i.e. source to receiver geometry but also for absolute positioning, i.e. geographical positioning. Considering the high-resolution imaging objective, optimal positioning accuracy should therefore reach a horizontal and vertical precisions of 2 and 0.2 meters, respectively. 


\section{TECHNOLOGICAL DEVELOPMENTS}

The hydrophones should withstand high hydrostatic pressure without a loss of sensitivity. The actual hydrophones consist of piezoelectric ceramic cylinders with end caps, this technology is capable to withstanding pressure to 700 bars and was used in most places in the design of deep towed streamers (Breitzke and Bialas, 2003, Leon et al., 2009, Rowe and Gettrust, 1993, Wood et al., 2008).

Given the exceptionally low noise level of the environment in deep-towed acquisition, each seismic trace consists in a single hydrophone. Because of the number of hydrophones and thus to the number of electrical wires, it is not possible to use analog technology, therefore digital hydrophones were designed taking advantage of Ethernet transfer protocol. Ethernet switches are included throughout the streamer to reduce the number of electrical wires.

The development of digital hydrophones (Fig. 1) took advantage of the inner cavity, at atmospheric pressure, of the cylindrical stack of ceramics to house the electronic board. The multi-layer technology was used to optimize the size of the board, the dimensions of which are $18 \mathrm{~mm} \mathrm{x} 70 \mathrm{~mm}$. The kernel of the electronic board is a 32-bit microcontroller allowing local numerical data processing. The microcontroller includes an Ethernet bootloader allowing potential reprogramming of the board while integrated in the streamer. The function of the hydrophone electronic board is four-fold : 1) an analog signal conditioning stage (band-pass filtering: $150-3000 \mathrm{~Hz}$ and pre-amplification: $26 \mathrm{~dB}$ ), 2) an analog to digital converter (24 bits, $10 \mathrm{kHz}$ ), 3) an Ethernet kernel and 4) a MEMS sensor (pitch, roll and heading). Each electronic board, on reception of a trigger signal delivered by the seismic source, collects 1 second of acoustic signal and sends it over the Ethernet network. The MEMS data are embedded in the seismic data. The hydrophones are HTI90 (sensitivity without pre-amplifier: $-186 \mathrm{~dB}$ ref $1 \mathrm{~V} / \mu \mathrm{Pa}$ ) from HighTech Inc., the electronic board was embedded by the hydrophone manufacturer.

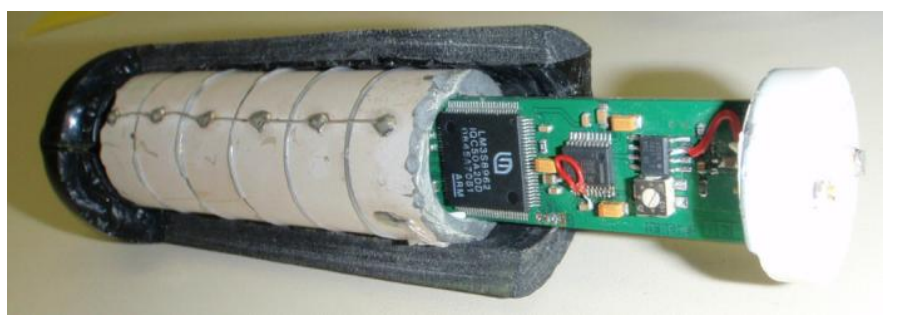

Fig. 1. Exploded view of the digital hydrophone, the coating was removed to expose the electronic board in the stack of ceramics.

The Ethernet switches were designed to collect single hydrophone data in order to merge the Ethernet flow. Each switch handles 8 Ethernet ports ( $7 \mathrm{in}, 1$ out), the electronic board being housed in a titanium cylinder $(46 \mathrm{~mm}$ diameter, $266 \mathrm{~mm}$ long excluding connectors). The purpose of the switch electronic board is three-fold: 1) Ethernet kernel, 2) power conditioning, and 3) trigger conditioning. 
The prototype streamer is made of 4 independent acoustic sections of 13 hydrophones and 2 Ethernet switches each, the individual electrical scheme of these sections includes 8 wires (i.e. 32 wires for the whole streamer) : 2 wires for power, 2 wires for trigger and 4 wires for the Ethernet connection $\left(\mathrm{Rx}^{+}, \mathrm{Rx}-, \mathrm{Tx}+, \mathrm{Tx}-\right)$.

The hydrophones and the switches were incorporated in a conventional oil-filled streamer by Sercel. The outer diameter of the streamer is $55 \mathrm{~mm}$, the skin is $2 \mathrm{~mm}$ thick. The streamer weights $500 \mathrm{~kg}$ in air, it is balanced (Isopar M) to be neutrally buoyant for a temperature of $2^{\circ} \mathrm{C}$ and a salinity of $33 \mathrm{~g} / \mathrm{l}$. The buoyancy can be adjusted by adding lead strips to meet the local environmental values. Because of the length of the titanium containers, which limit the radius of curvature to 1 metre, a dedicated hydraulic winch was developed to host the streamer (Fig. 2).

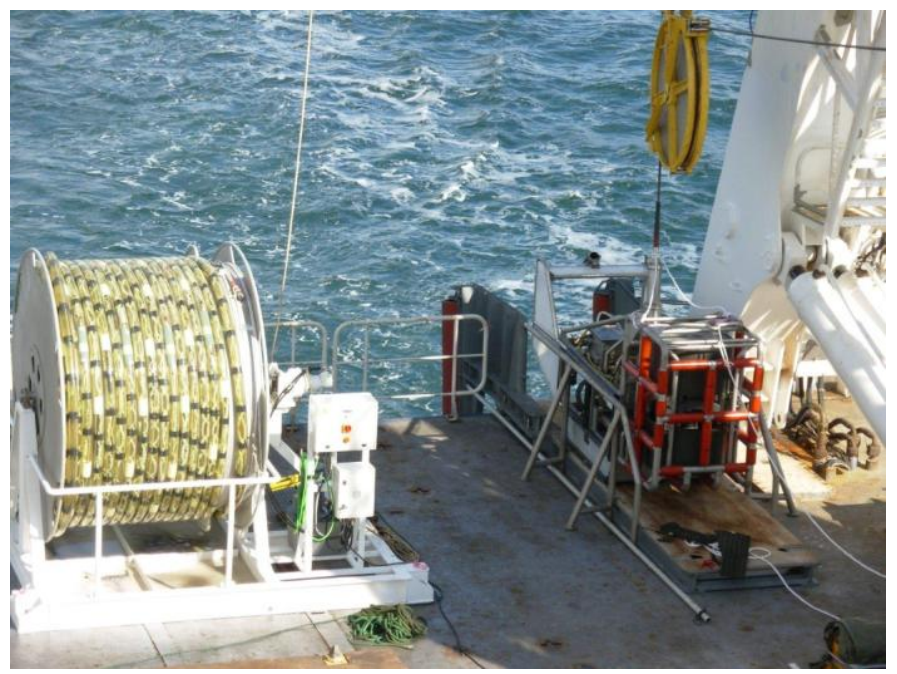

Fig. 2. The seismic streamer on its winch (left), together with the SYSIF towed fish hosting the seismic source (right)

The streamer is connected to the SYSIF towed fish, hosting the seismic source, through a 32 pins pressure-resistant connector. The armoured electro-optical cable delivers the power to the towed fish and receives the Ethernet data flow $(\cong 10$ Mbits / acquisition). A bi-directional Focal optical telemetry transmits the Ethernet seismic data, the navigation data and the different controls to the surface. The trigger signal is sent by the SYSIF seismic source through the cable to trigger a Meinberg GPS clock, to precisely date the seismic data.

The navigation of the seismic source is achieved through an acoustic $120 \mathrm{kHz}$ Simrad altimeter, a Paroscientific pressure sensor and a miniature Xsens attitude and reference system. The positioning is ensured by the Acoustic Ultra Short Base Line (USBL) iXblue Posit 14-16kHz. The depth/altitude/attitude data are acquired at sampling rates of $10 \mathrm{kHz}$ and sent to the surface, through the optical telemetry, where they are recorded for processing purposes. The streamer behaviour is monitored with the pitch/roll/heading sensor included in each hydrophone.

\section{IMPLEMENTATION}


124 Operating a deep-towed high-resolution seismic is significantly different from conventional surface-towed seismic systems

125 (Marsset T. et al., 2010; Leon et al., 2009). The towing depth, and thus the altitude, of the source is controlled by an electro126 optical tow-cable. The cable is paid out or hauled in order to maintain a constant altitude above the sea floor. Every action of 127 the winch changes the geometry of the acquisition as any displacement of the seismic source will impact on the streamer shape. The attitude sensors within the hydrophones in the streamer are recorded at the same rate as the shooting rate, i.e. between 1 and 3 seconds, according to the bathymetry. Therefore, high-frequency streamer motion cannot be properly monitored and the instructions are to minimize actions on the winch during the acquisition of a seismic profile. The maximum towing speed is 2 knots.

The shooting rate and the recording time window are calculated using a ray tracing algorithm in order to avoid multiple reflections from the sea surface. Given the frequency content of the seismic source, the sea-surface roughness distorts the signal, making it impossible for the processing to remove multiple rays.

The frequency of the acoustic USBL beacon is $14-16 \mathrm{kHz}$. This frequency is well outside the frequency bandwidth of the seismic source, nevertheless it produces bursts of noise on the seismic records: the USBL transmitting rate is therefore synchronised with the seismic-source trigger to prevent interference in the recording window. An OSEA acoustic synchronisation tool controls all acoustic equipment, the seismic source being the master and all other equipment having their own dedicated time slot.

The acquisition system monitors seismic data through a simple correlation / amplitude retrieval processing in order to provide a seismic section of a selected hydrophone, the data being uncorrected from source and streamer motions. This acts as a Quality Control (QC) tool to detect any failure in the acquisition chain, either seismic source, streamer or GPS clock malfunctions. Depth and altitude information are used to drive the winch to maintain the system at the target depth / altitude.

During the scientific « Prisme 2» cruise onboard French R/V «L'Atalante », in August 2013, 250 miles of multichannel deep-towed seismic data were successfully acquired off Corsica (water depth 600-900 m) and in the Gulf of Lion (water depth $2000 \mathrm{~m}$ ). Additional single-channel deep-towed seismic data were acquired on the Ligurian margin (water depth 500$2000 \mathrm{~m}$ ). One of the aims of the «Prisme $2 »$ cruise was to study and to analyse some massive submarine landslides present in the western Mediterranean sea.

The following sections will focus on the presentation of a short seismic profile ( 2 miles), where there is much evidence of geological features such as slides or fluid chimneys. The data set consists of 1500 records acquired with a shooting rate of 
one per 2.5 seconds. The water depth was between 850 and $875 \mathrm{~m}$. At this early stage of development of the multichannel streamer, its altitude was kept conservatively high, at $150 \mathrm{~m}$ above the sea floor, in the absence of experience of its behaviour behind the towed-fish. Although this altitude allowed us to assess for the feasibility of deep-towed high-resolution seismic imaging, a lack of precision in the determination of seismic velocity was anticipated.

\section{DATA PROCESSING}

The processing sequence is split into two distinct flows: positioning processing and seismic processing

\section{A. Positioning processing}

The positioning workflow aims at obtaining the absolute positions of both source and receivers (Fig. 3). Each sensor comes with its own acquisition rate. The raw data are processed at their own rates, the processed data are then interpolated at the proper trigger times.

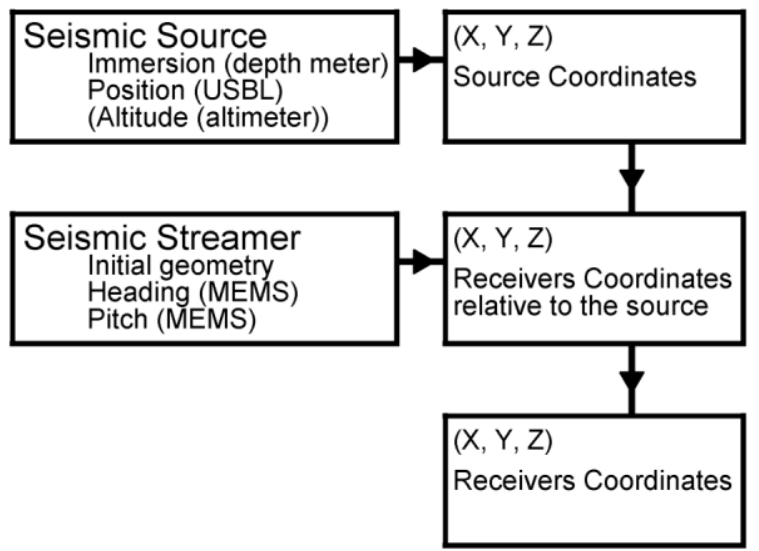

169

Fig. 3. Positioning workflow.

171 The altitude data are not accurate enough to be used for geometry processing (Fig. 4, left). The half-power beam width of the

172 Simrad altimeter is $15^{\circ}$ (diameter $40 \mathrm{~m}$ at sea floor), thus $3 \mathrm{D}$ effects cannot be avoided in the detection of the seabed. The 173 altitude is used in combination with the depth and compared with additional multibeam bathymetry to assess eventual 174 positioning error. 
Altitude / Depth

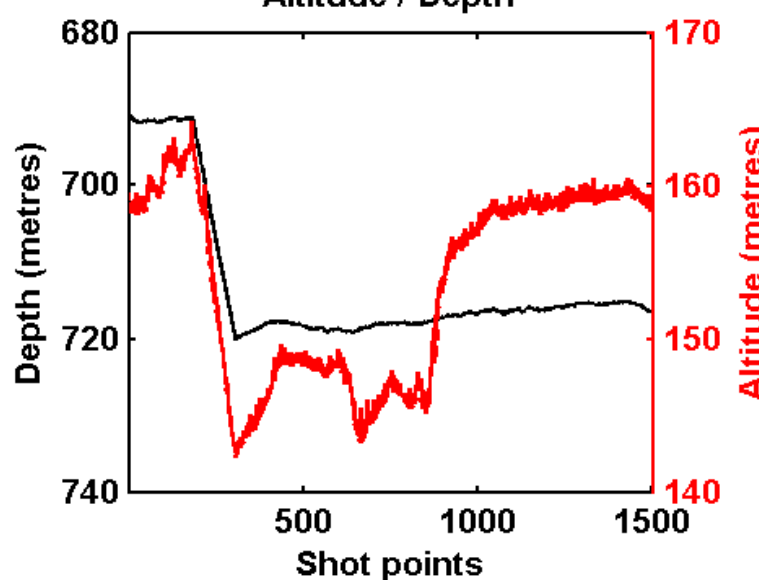

Position

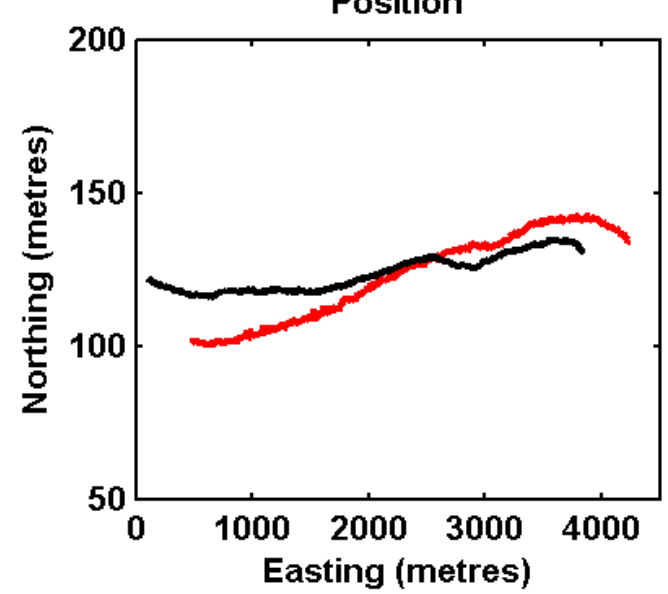

Fig. 4. Left -Depth (black curve) / altitude (red curve) of the seismic source. Right - Track lines of both vessel (black curve) and tow-fish (red curve). A coordinate offset was used for confidentiality purpose

The depth of the tow fish has a precision of $0.01 \%$, i.e. $\cong 0.1 \mathrm{~m}$ for the current data set. Depth data are screened, low-pass filtered $(0.1 \mathrm{~Hz})$, and interpolated at the proper trigger time (Fig. 4, left).

The horizontal distance between the vessel and the tow fish averaged 400 metres for a mean towing depth of 700 metres, the measurement angle of the USBL beacon of the vessel is therefore evaluated to $30^{\circ}$, well inside the specifications of the product. An evaluation of the variation of the towed fish positions yielded a median value of less than 1 metre for the current data set (Fig. 4, right).

The $(\mathrm{X}, \mathrm{Y}, \mathrm{Z})$ absolute positions of the seismic source are calculated from USBL and depth-processed data.
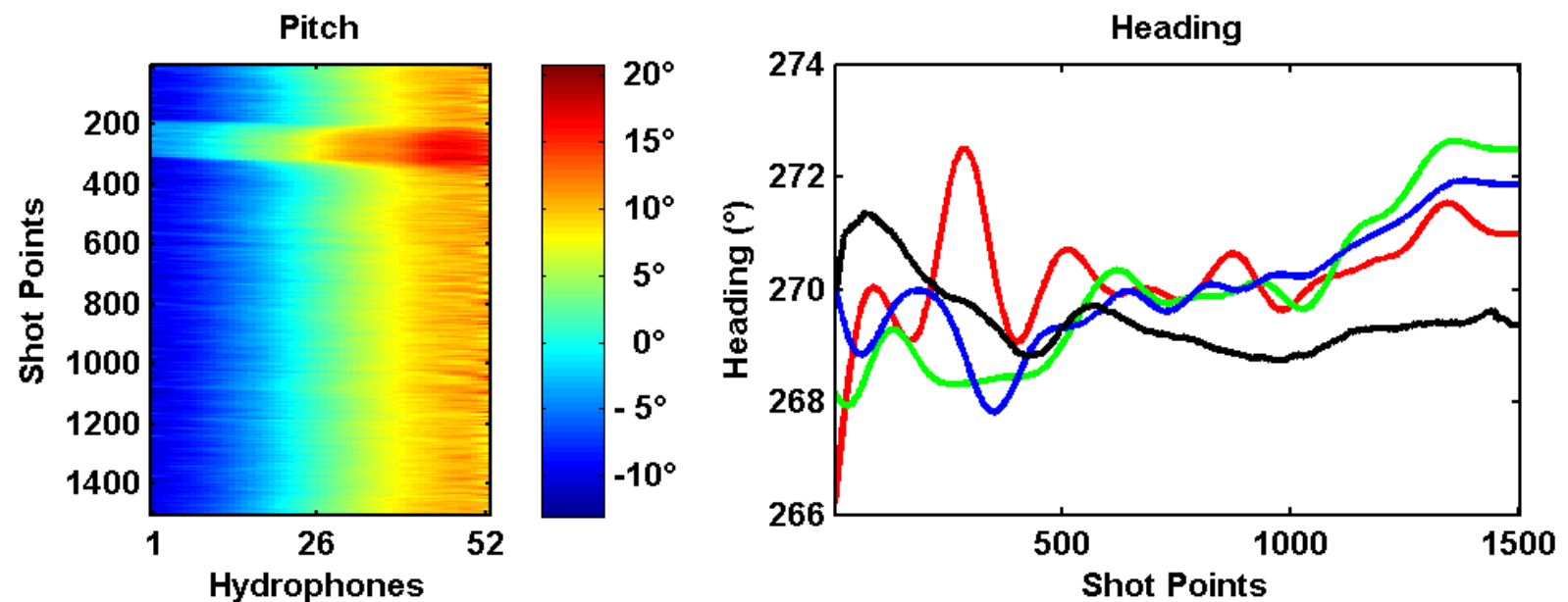

Fig. 5. : Left : Pitch data from the hydrophone MEMS sensors. Right : Heading data from the hydrophone MEMS sensors, hydrophone 1 (red curve), hydrophone 26 (green curve) and hydrophone 52 (blue curve), the dark curve corresponds to the 
193 The pitch values of the 52 hydrophones are extracted from the seismic data. The pitch raw data displays the presence of the 194 sensors offsets biases. These offsets were previously measured in laboratory and are removed from the pitch data. A smooth 195 low-pass filter $\left(0.05 \mathrm{~m}^{-1}\right)$ is applied on a Common Shot Gather basis to remove unreliable, high wave number variations (Fig. 1965, left).

It appears that the mean streamer shape is driven by the local weight of the electronic equipment inside the streamer: the streamer is neutrally buoyant as a whole, nevertheless the number of electrical wires is much higher toward the head of the streamer. The first half of the streamer is gently dipping downward $\left(\cong-10^{\circ}\right)$, whereas the tail is gently rising $\left(\cong+15^{\circ}\right)$. The mean vertical depth-range of the streamer, therefore lies between $\cong-5 \mathrm{~m}$ (middle) and $\cong+10 \mathrm{~m}$ (tail) with respect to the seismic source. Figure 4 (left) depicts a sharp action on the winch between shot 200 and shot 300: the impact on the streamer shape is clearly observable on the pitch values with the propagation of the deformation along the streamer (Fig. 5, left).

The processing of the MEMS heading sensors is similar to the former sequence. The heading values of the different hydrophones are extracted and corrected from their offsets measured in laboratory. The heading data are far more noisy than pitch data. The impact of vertical motion of the streamer on the near-offset heading sensors can be observed by comparing pitch data (Fig 5, left) and heading data (Fig 5, right, hydrophone 1, red curve) between shot number 200 and shot number 300. A $0.2 \mathrm{~Hz}$ low-pass filter was applied on a common-receiver basis to look for the presence of streamer feathering. The mean calculated absolute drift angle is $2^{\circ}$, i.e. 4 metres of lateral offset for the far hydrophone, and therefore it was not taken into account in the processing of the present data set.

213 The relative $(\mathrm{X}, \mathrm{Z})$ hydrophones positions, with respect to the tow fish, are calculated using the processed pitch values and 214 the hydrophones offsets (Fig 7, upper).

The absolute $(\mathrm{X}, \mathrm{Y}, \mathrm{Z})$ hydrophones positions are calculated by projecting their relative positions in a $2 \mathrm{D}$ plane behind the towed fish absolute positions.

\section{B. Seismic processing}

The seismic workflow (Fig. 6) is split into two distinct sequences: 1) Signal processing, i.e. to provide end-users with legible single channel seismic time sections, 2) Imaging processing, i.e. to obtain a preserved amplitude depth section tailored for seismic inversion. 


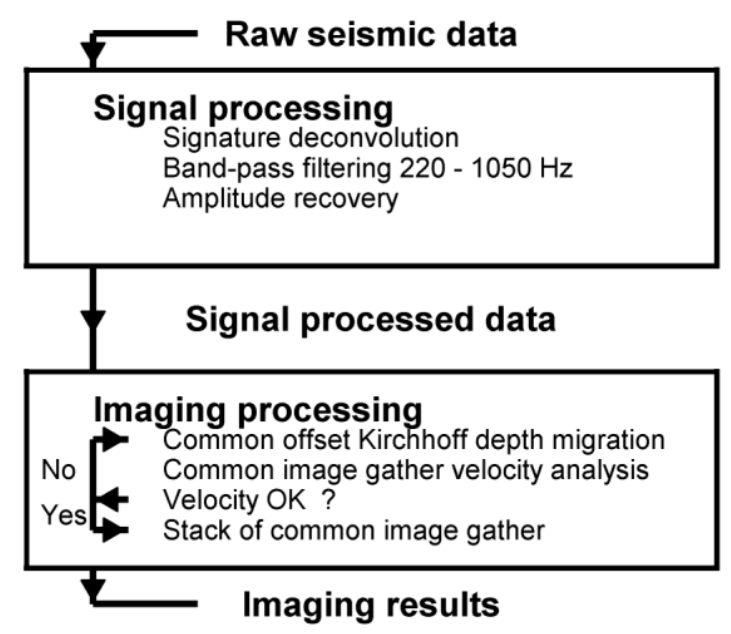

Fig. 6. Seismic processing workflow

1) Signal processing

The electric pilot source signal is a 100 milliseconds Linear Frequency Modulation (Linear FM) ranging from 220 to 1050 Hz. This initial signal is amplitude modulated in order to obtain a flat acoustic signal with a constant Sound Level of $196 \mathrm{~dB}$ ref $1 \mu \mathrm{Pa} @ 1 \mathrm{~m}$ over the entire frequency bandwidth.
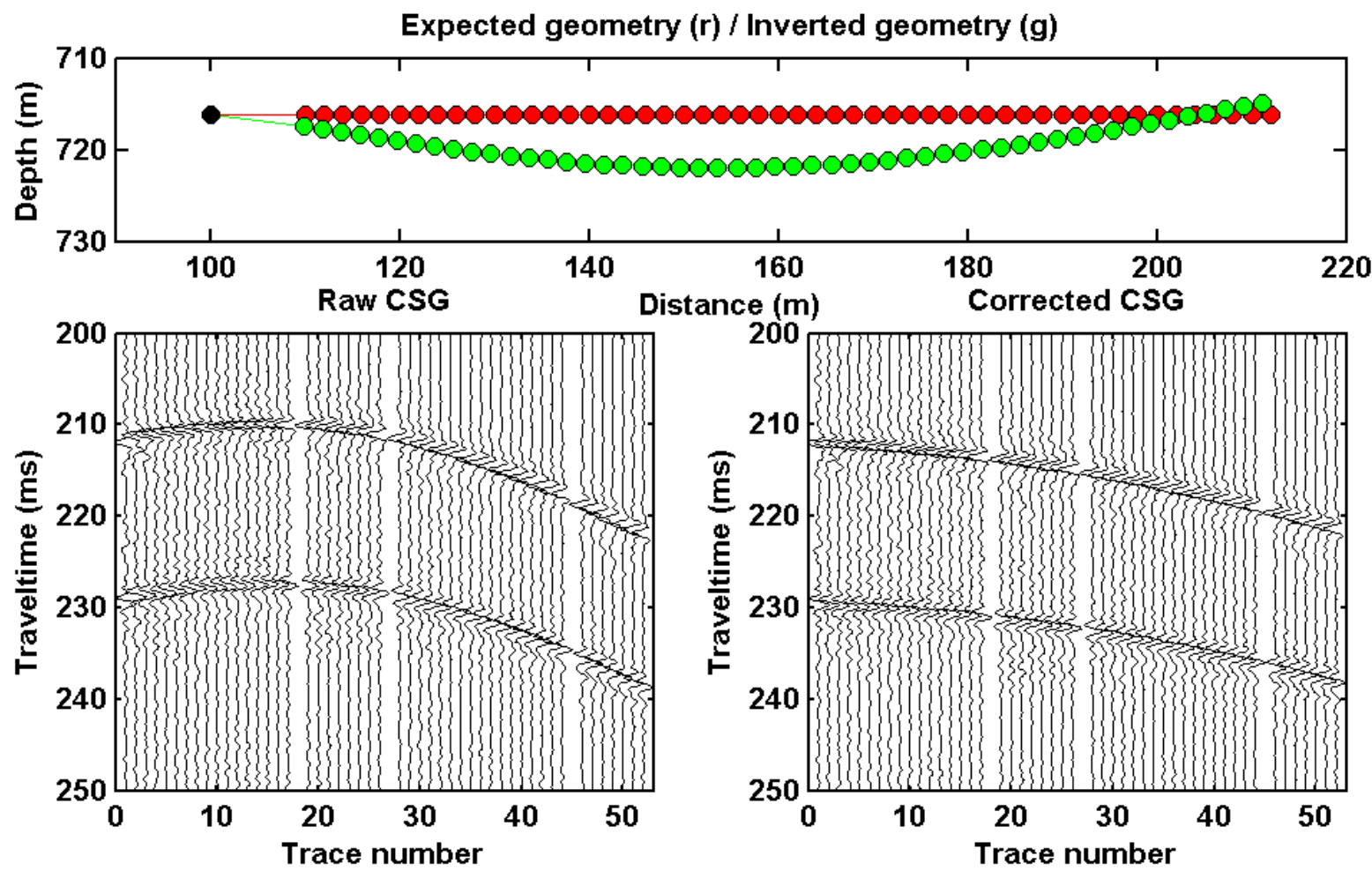

Fig. 7. Upper : Streamer geometry as a result of positioning processing. Lower left : Common Shot Gather (CSG) after signal processing. Lower right : CSG after constant datuming

234 The source far field signature was previously recorded (Ker et al., 2010). This signature is valid in the main lobe of directivity of the seismic source $\left(40^{\circ}\right)$ and consequently the direct arrivals are muted. The signal processing sequence is 
limited to signature deconvolution / band pass $(220-1050 \mathrm{~Hz})$ filtering / amplitude recovery. A signal processed Common Shot Gather (CSG) is presented Fig 7 (lower left) where the shape of the sea-bottom reflection reflects the geometry of the streamer. A constant datum shift is calculated based on the results of the positioning processing (Fig 7, upper) and applied to the CSG (Fig 7, lower right) to illustrate the validity of the streamer geometry inversion.

\section{2) Seismic imaging processing}

The particular geometry of the acquisition where the source receiver geometry is perpetually changing, does not allow the seismic data to be processed in a "conventional" marine sequence: Common Mid Point sorting - Normal Move Out - Stack (Asakawa et al., 2009). We adapted a pre-stack processing approach in order to take into account the real (X,Y,Z) positions of both sources and receivers in the imaging process. The approach applies Kirchhoff depth migration to each Common Receiver Gather (CRG or Common Offset Gather). The different migrated sections are then sorted into Common Image Gathers (CIG), i.e. to build an image of the same terrain location obtained from the different source-receiver offsets. If the migrated traces of a CIG are identical for the different offsets this will confirm the validity of the velocity model. This approach is commonly carried out in a layer-stripping iterative scheme to obtain, simultaneously, the variation of P-wave velocity with depth and the imaging result.
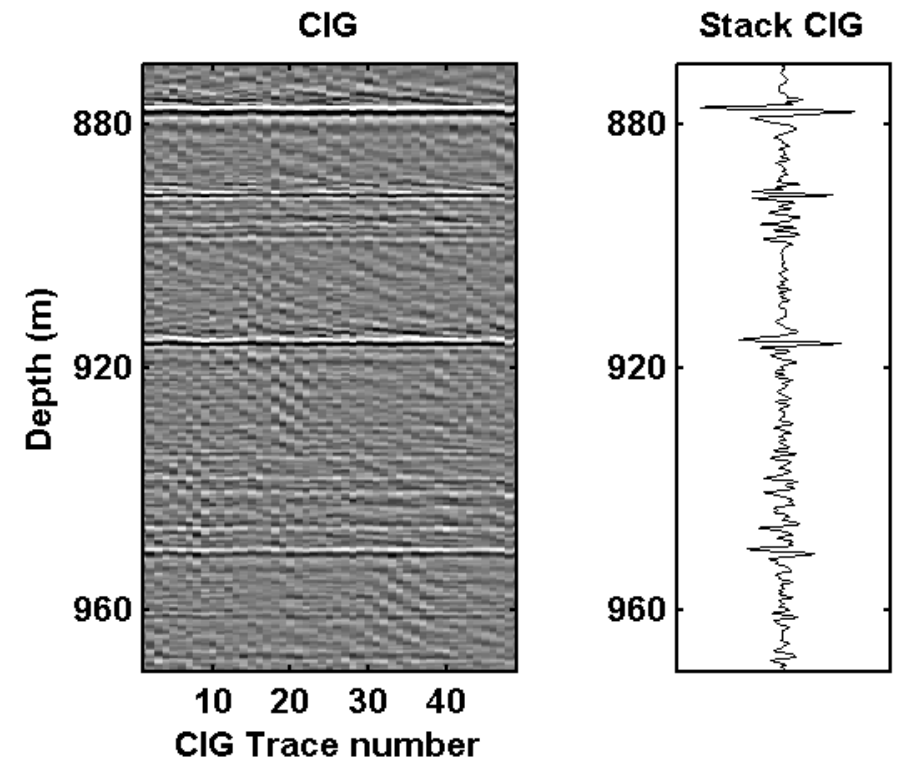

252

Fig. 8 Constant velocity Common Image Gather $(C I G)$ : the CIG (left) with flat reflectors shows no evidence of velocity variations. The corresponding stack (right) is presented to illustrate the gain in Signal/Noise.

However, as previously mentioned, the altitude of the system during the sea trials was set high, and, for this data set, the source-receiver offsets are too small relative to the depth of the seabed to obtain reliable information on velocity (Fig 8), 
therefore, a constant velocity was used in the processing. Finally, the equivalent traces from the CIGs for each different source-receiver offset are stacked to obtain the final depth section.

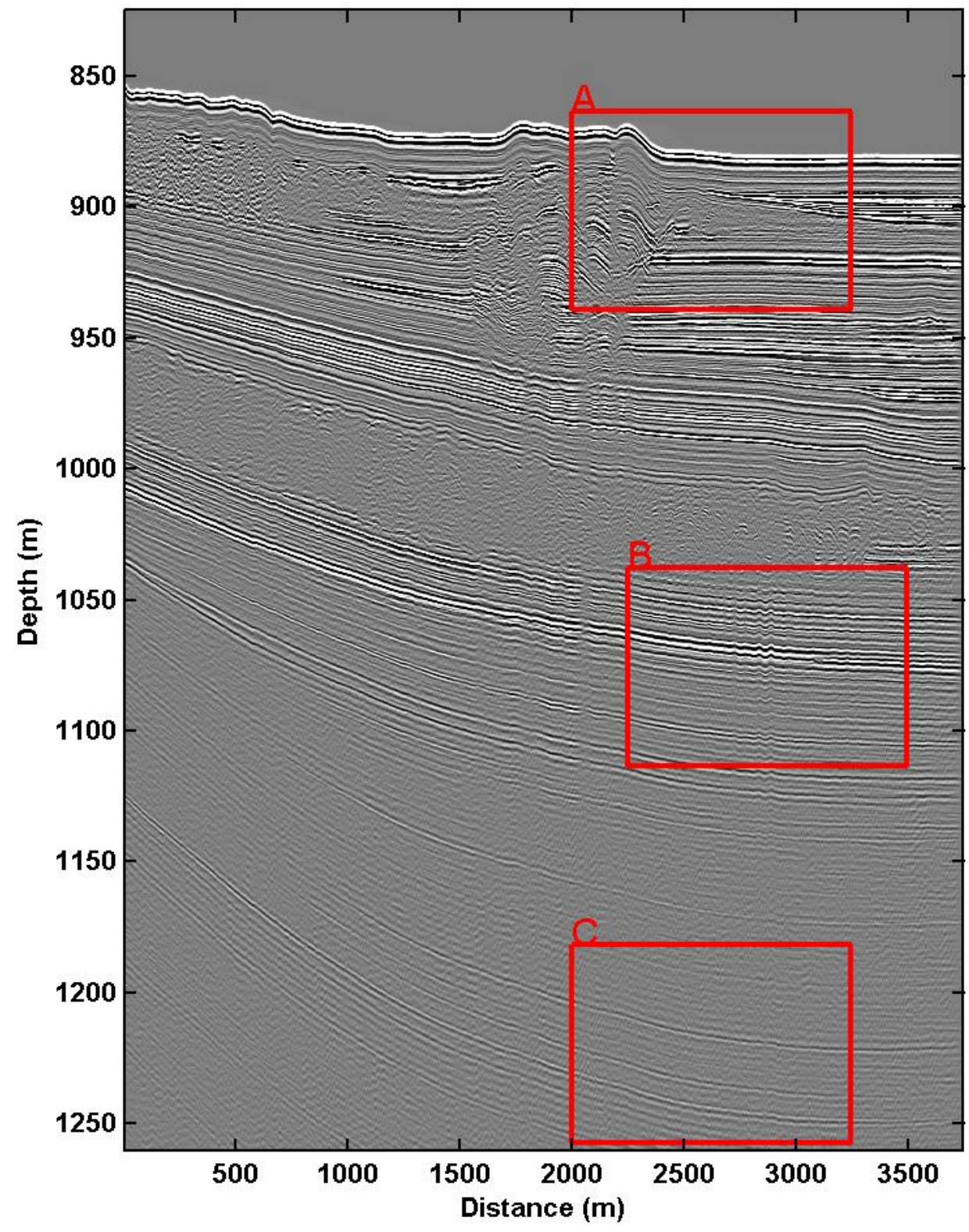

Fig. 9. Pre-stack depth migrated section.

262 The following parameters were used in the processing: horizontal sampling: $1 \mathrm{~m}$, vertical sampling $0.1 \mathrm{~m}$, velocity value:

$2631516 \mathrm{~m} / \mathrm{s}$ (obtained from expendable Conductivity-Temperature-Depth (XCTD) probes), migration aperture: $45^{\circ}$ (this 264 parameter was chosen based upon the existence of strong hyperbolae in the raw data). We incorporated an anti-alias filter in the migration algorithm in order to avoid spatial aliasing, which would have introduced noise into the final image. The method consists in filtering the common offset gathers in different frequency bandwidths that comply with aliasing requirement for the incidence angles for each offset, prior to migration.

\section{IMAGING RESULTS}


272 - Figure 9 presents the entire depth section where the penetration reaches 400 metres below sea floor (the vertical 273 exaggeration of the figure is $\cong 15$ ). The image features a sedimentary basin filled with turbiditic, hemipelagic and mass274 transport deposits. Two massive submarine landslides, 30 to 40 meters thick, recognizable with their chaotic seismic pattern, 275 extend from left to right. The youngest landslide is believed to have formed a so-called "compression ridge" which affects 276 the sea floor topography as well as the upper sedimentary layers in the middle of the section.
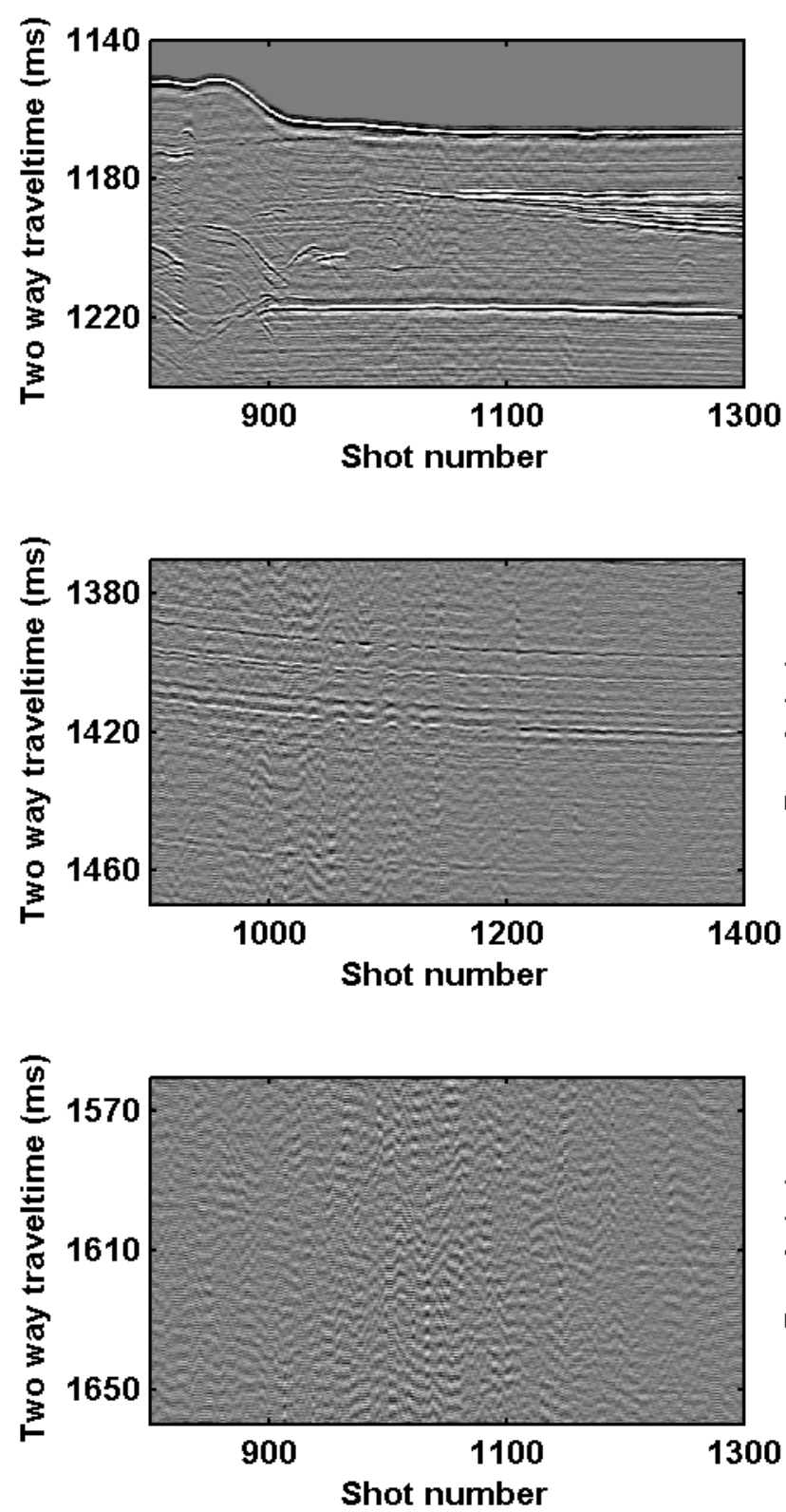

A

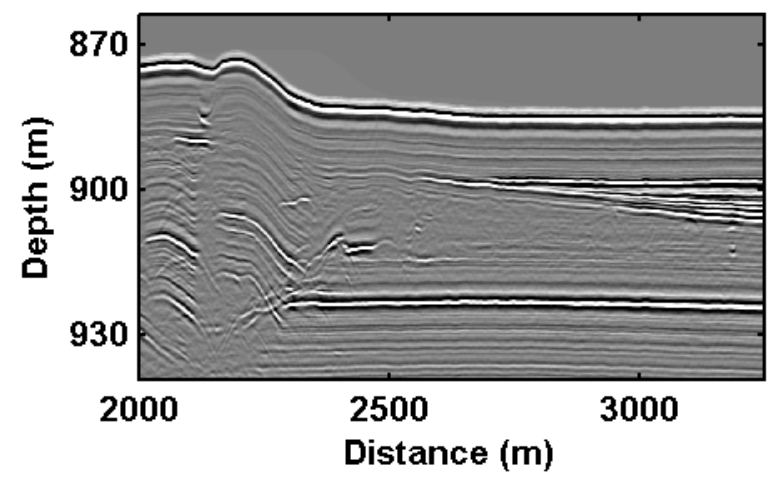

$\mathbf{B}$

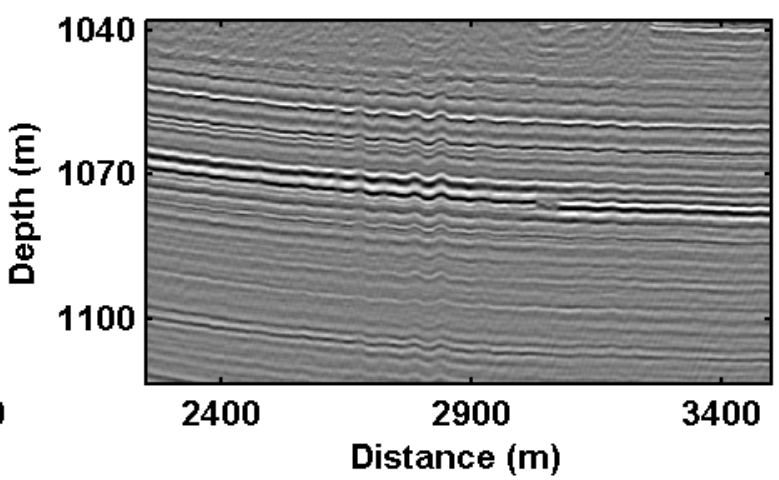

C

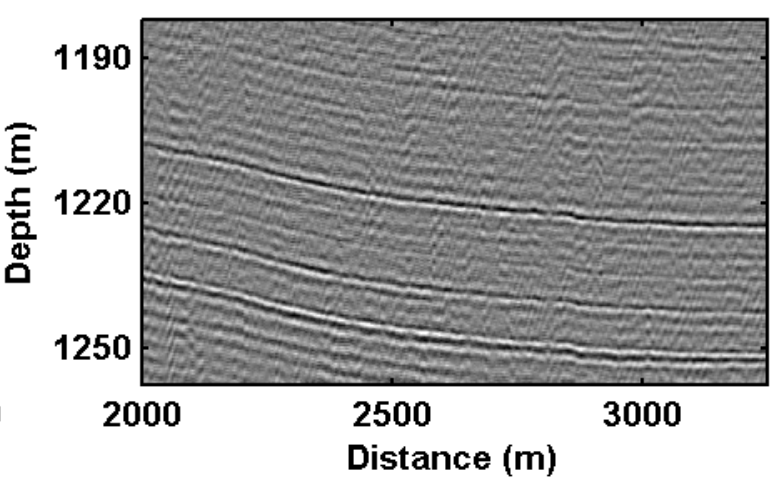

Fig. 10. Comparison of close-ups of single channel time sections (left) and corresponding pre-stack depth migrated sections (right). See text for explanation.

280 Figure 10 proposes a comparison of three close-ups of single channel time sections versus their corresponding migrated 281 image in order to emphasize the contribution of seismic imaging techniques. A constant datum shift was applied to the time sections to correct from the source vertical displacement for comparison purposes. 
- Figure 10 A illustrates the gain in Signal to Noise ratio $(\mathrm{S} / \mathrm{N})$. The Signal and Noise attributes are evaluated in selected windows on the sections envelope. The difference in $\mathrm{S} / \mathrm{N}$ between time and depth sections is evaluated to $12 \mathrm{~dB}$ whereas the theoretical gain, defined as the square root of the main fold, is $17 \mathrm{~dB}$.

- Figure $10 \mathrm{~B}$ illustrates the gain in lateral resolution. The migrated section displays reflectors undulations with an average wavelength of 60 meters. The theoretical lateral resolution of a monostatic monochromatic acquisition is limited by the width of the first Fresnel zone (70 metres for the current feature) and, consequently these undulations are barely observable on the time section. The theoretical lateral resolution of the migrated section is equal to the mean wavelength of the seismic signal (3 metres), but cannot be demonstrated on this data set.

- Figure $10 \mathrm{C}$ illustrates the gain in penetration. As a consequence of $\mathrm{S} / \mathrm{N}$ improvement, the penetration achieved on the depth migrated section reaches twice the one observed on the time section.

\section{CONCLUSION}

A prototype of a digital deep-towed multichannel streamer has been developed and the feasibility of performing highresolution multi-channel seismic imaging in deep water has been demonstrated. The gain in signal-to-noise ratio $(\mathrm{S} / \mathrm{N})$ doubles the penetration achieved in single-channel acquisition. The migration processing sequence improves the lateral resolution to 3 meters (mean wavelength of the signal), quadrupling the resolution achieved in single channel acquisition.

The ability to perform accurate velocity analysis has still to be demonstrated, which requires the streamer to be towed closer to the sea bottom. The excellent behavior of the streamer and the quality of the positioning equipment will make this possible during the next sea trials scheduled in 2014.

The development of an operational streamer will be started, taking into account the experience gained during the project.

\section{Acknowledgments:}

The development of the multichannel streamer was funded by Institut Carnot Ifremer EDROME.

The authors are indebted to the scientific party and to the crew of the "Prisme 2" cruise, onboard French R/V L'Atalante, for their permission to perform these sea trials during a scientific survey. The GENAVIR operating team of the SYSIF source is warmly thanked for their skill as well as for their kindness.

\section{Reference:}

Asakawa, E., Mizohata, S., Inamori, T., Saeki T., 2009. "High resolution, deep-tow seismic survey to investigate methane hydrate-bearing sediments, Nankai Trough, Offshore Japan", presented at OCEANS 2009 - Europe, Bremen 11-14 may 2009 
316 Breitzke, M., Bialas, J., 2003. A deep-towed multichannel seismic streamer for very high-resolution surveys in full ocean depth First Break, 21, 59-65.

318 Chapman, N.R., Gettrust, J.F., Walia, R., Hannay, D., Spence, G.T., Wood, W.T., Hyndman, R.D., 2002, "High Resolution deep-towed multichannel seismic survey of deep sea gas hydrates off western Canada", Geophysics, 67, 1038-1047

Gettrust, J.F., Wood, W., Spychalski, S., 2004, "High-resolution MCS in deepwater", The leading Edge, 23, 374-377

W. Wood, P. Hart, D. Hutchinson, N. Dutta., F. Snyder, R. Coffin, and J. Gettrust, 2008. "Gas and gas hydrate distribution

He, T., Spence, G., Wood, W., Riedel, M., Hyndman, R., 2002, "Imaging a hydrate-related cold vent offshore Vancouver Island from deep-towed multichannel seismic data", Geophysics, 74, B23-B26

Ker, S., Marsset, B., Garziglia, S., Le Gonidec, Y., Gibert, D., Voisset, M., Adamy J., 2010, " High-resolution seismic imaging in deep sea from a joint deep-towed/OBH reflection experiment: application to a Mass Transport Complex offshore Nigeria", Geophys. J. Int., 182, 1524-1542.

Leon, P., Ker, S., Marsset, B., Le Gall, Y., Voisset M., 2009, " SYSIF a New Seismic Tool for Near Bottom very High Resolution Profiling in Deep Water" ", presented at OCEANS 2009 - Europe, Bremen 11-14 may 2009

Marsset, T., Marsset, B., Ker, S., Thomas, Y., Le Gall, Y., 2010, "High and very high resolution deep-towed seismic system: Performance and examples from deepwater geohazard studies", Deep-Sea Research Part I, 57(4), 628-637 occurrence influencing a submarine landslide and pockmark formation and distribution in deepwater Nigeria", Earth and Planetary Science Letters, 375, 78-91

Rowe, M., Gettrust, JF., 1993, "Fine structure of methane hydrate-bearing sediments on the Blake outer ridge as determined from deep-towed multichannel seismic data", J. Geophys. Res., 98, 463-473

Sultan, N., Marsset, B., Ker, S., Marsset, T., Voisset, M., Vernant, AM.,. Bayon, G., Cauquil, E., Adamy, J., Colliat, JL., Drapeau, D., 2010, "Hydrate dissolution as a potential mechanism for pockmark formation in the Niger delta", J. Geophys. Res., 115, B8

Sultan, N., Riboulot, V., Ker, S., Marsset, B., Géli, L., Tary, JB., Klingelhoefer, F., Voisset, M., Lanfumey, V., Colliat, JL., Adamy, J., Grimaud, S., 2011, " Dynamics of fault-fluid-hydrate system around a shale-cored anticline in deepwater Nigeria ", J. Geophys. Res., 116, B12

Walia, R., Hannay, D., 1999, "Source and receiver geometry corrections for deep-towed multi-channel seismic data", Geophys. Res. Lett., 26, 1993-1999

Wood, W., Gettrust, JF., Spychalski, S., 2003, "A new deep-towed, multi-channel seismic system". Sea Technology, 44, 4449, 
346 Wood, W., Hart, P., Hutchinson, D., Dutta., N., Snyder, F., Coffin, R., Gettrust, J., 2008, "Gas and gas hydrate distribution 347 around seafloor seeps in Mississipi Canyon, Nothern Gulf of Mexico, using multi-resolution seismic imagery", Marine and 348 Petroleum Geology, 25, 952-959 